\title{
Thermal Analysis of Multibarrier Interior PM Synchronous Machine Using Lumped Parameter Model
}

\author{
Ayman M. EL-Refaie, Student Member, IEEE, Nathan C. Harris, Thomas M. Jahns, Fellow, IEEE, and \\ Khwaja M. Rahman, Member, IEEE
}

\begin{abstract}
This paper presents a lumped-parameter thermal model for a multi-barrier interior PM synchronous machine. The model consists of a network of 12 thermal resistances that make it possible to estimate temperatures at 9 critical points inside the machine including the stator end windings, rotor magnets, and the bearings. The details of the model are presented and two machines are analyzed, including a $6 \mathrm{~kW}$ 12-pole automotive starter/alternator and a $0.5 \mathrm{~kW}$ 4-pole electric water pump machine. The lumped-parameter model results for both machines demonstrate good agreement with results obtained using detailed thermal finite element analysis.
\end{abstract}

Index Terms-AC machines, brushless machines, equivalent circuits, losses, optimization methods, permanent magnet machines, synchronous machines, thermal factors.

\section{INTRODUCTION}

$\mathbf{I}$ NTEREST in interior permanent magnet (IPM) synchronous machines has been growing during recent years for a variety of new industrial, commercial, and transportation applications. IPM machines have several attractive characteristics for these applications, including brushless design, high efficiency, high torque/power density, and wide constant-power speed range. One of the application areas where there has been particular interest in these machines is automotive propulsion and accessories. IPM machines are already used in production hybrid electric vehicles such as the Toyota Prius, and they are being evaluated for other critical applications including direct-drive starter/alternator machines (see Fig. 1) [1].

The design of IPM machines requires that thermal constraints be met in the process of meeting electromechanical torque and power specifications. The automobile presents particularly challenging thermal requirements since under-the-hood temperatures can rise to $150 \operatorname{degC}$ or higher.

Monte Carlo optimization has proven to be an effective tool for designing IPM machines to minimize their cost while meeting a combination of performance and environmental constraints [2]. However, Monte Carlo optimization requires that very large numbers of candidate machine designs_-often numbering in the millions-be rapidly evaluated to determine

Manuscript received January 13, 2003. This work was supported by the U.S. National Science Foundation under Award EEC-9731677.

A. El-Refaie and T. Jahns are with the Electrical and Computer Engineering Dept., University of Wisconsin-Madison, Madison, WI 53706 USA.

N. Harris is with Kimberly Clark Corp., Neenah, WI.

K. Rahman is with GM Advanced Technology Center, Torrance, CA.

Digital Object Identifier 10.1109/TEC.2004.827011

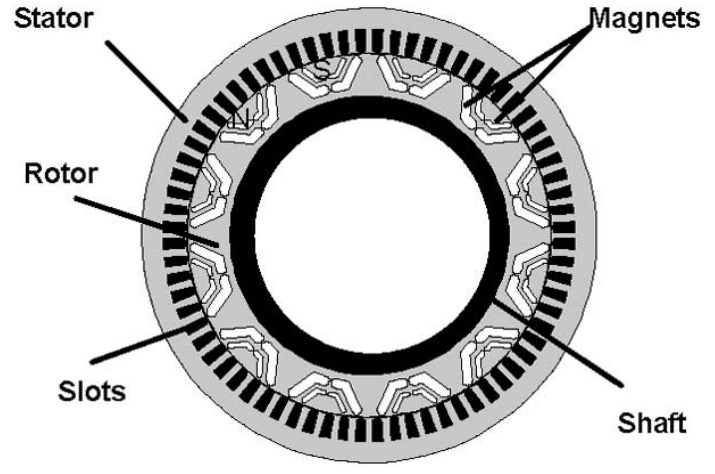

Fig. 1. The 6-kW IPM starter/alternator machine cross section [1].

their performance and thermal characteristics. These thermal calculations are complicated by the fact that three-dimensional analysis is required to determine machine temperatures at key points such as the end windings that often are the hottest elements in the machine. Evaluation of each candidate machine's thermal performance using finite element analysis (FEA) is invariably too time-consuming to be acceptable, even with modern computing equipment.

Lumped-parameter thermal models provide an appealing means of estimating the key temperatures inside an electrical machine much more rapidly than with FEA, albeit with some loss in estimation accuracy. The majority of reported work to date on electrical machine lumped-parameter thermal models has addressed induction machines [3]-[6] or wound field synchronous machines [7]. Some of these models are quite sophisticated with a high number of nodes that require detailed information about the machine's construction in order to properly evaluate.

There have been a smaller number of reports describing lumped-parameter models for permanent magnet synchronous machines. Such a model is presented in [8] for a surface-mounted magnet machine. Lumped-parameter thermal analysis is also used in [9] to optimize the design of another special class of PM synchronous machine in which the magnets are inset along the rotor periphery.

More recent work by Lindström and Luomi [10] presents a detailed lumped-parameter thermal model for a surface-mounted water-cooled permanent magnet machine that can be used for both steady-state and transient analysis. Although the three-dimensional nature of the machine construction is captured by this model, the number of discrete 


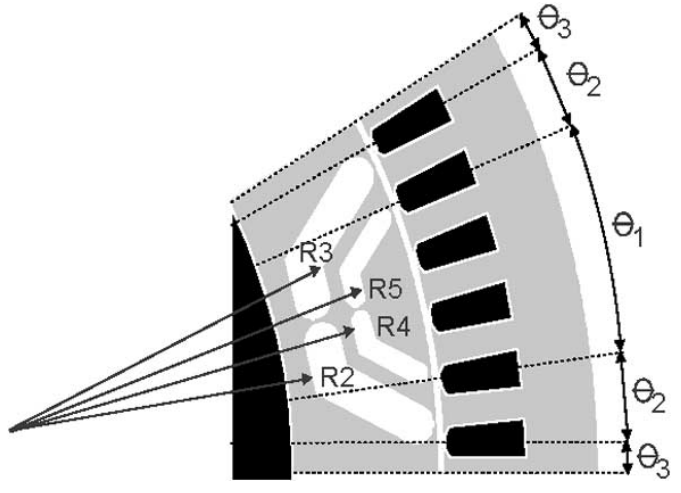

Fig. 2. Cross section of one pole of the machine including identification of key radii and angles.

thermal nodes has been reduced to less than 10 . Such streamlining of the model makes it possible to focus attention on the temperatures of key points inside the machine including the rotor magnets and end windings while limiting model complexity.

This paper presents a modified version of the lumped-parameter model described in [10] for thermal analysis of a multi-barrier interior permanent magnet machine. This model has been specifically developed and exercised for steady-state thermal analysis of water-cooled IPM machines with two magnet barriers per pole as shown in Fig. 1. However, the model can be flexibly extended to higher or lower numbers of magnet barriers and other machine cooling methods.

Results are presented in this paper from applying this lumped-parameter thermal model to two different IPM machines designed for automotive applications-a $6 \mathrm{~kW}$ direct-drive starter/alternator and a $0.5 \mathrm{~kW}$ electric water pump. Confidence in the validity of this model is established by comparing its predictions with those of finite-element analyses that were carried out for the same machines.

\section{Thermal Model Details}

\section{A. Thermal Model Equivalent Circuit}

The $6 \mathrm{~kW}$ IPM starter/alternator machine referenced in the Introduction [1] will be used as the basis for presenting the details of this lumped-parameter thermal model. Fig. 2 shows the cross section of one pole of this 12-pole machine with identification of all the key radii and angles that will be used in deriving the elements of the model.

The thermal model equivalent circuit is shown in Fig. 3, consisting of a 10-node network that captures all key machine temperatures. This network has been designed to provide access to all key elements inside the machine, making it possible, for example, to inject losses individually into each of the two magnet layers.

Since both surface and interior PM machines have essentially identical stator structures, the thermal model in Fig. 3 differs from that developed in [10] only in regards to the rotor model. More specifically, the only thermal resistances that will be different in this model are $R_{t h 10}, R_{t h 11}$, and $R_{t h 12}$. Detailed expressions for evaluating all of the other thermal resistances in Fig. 3 can be found in [10] and are not repeated here.

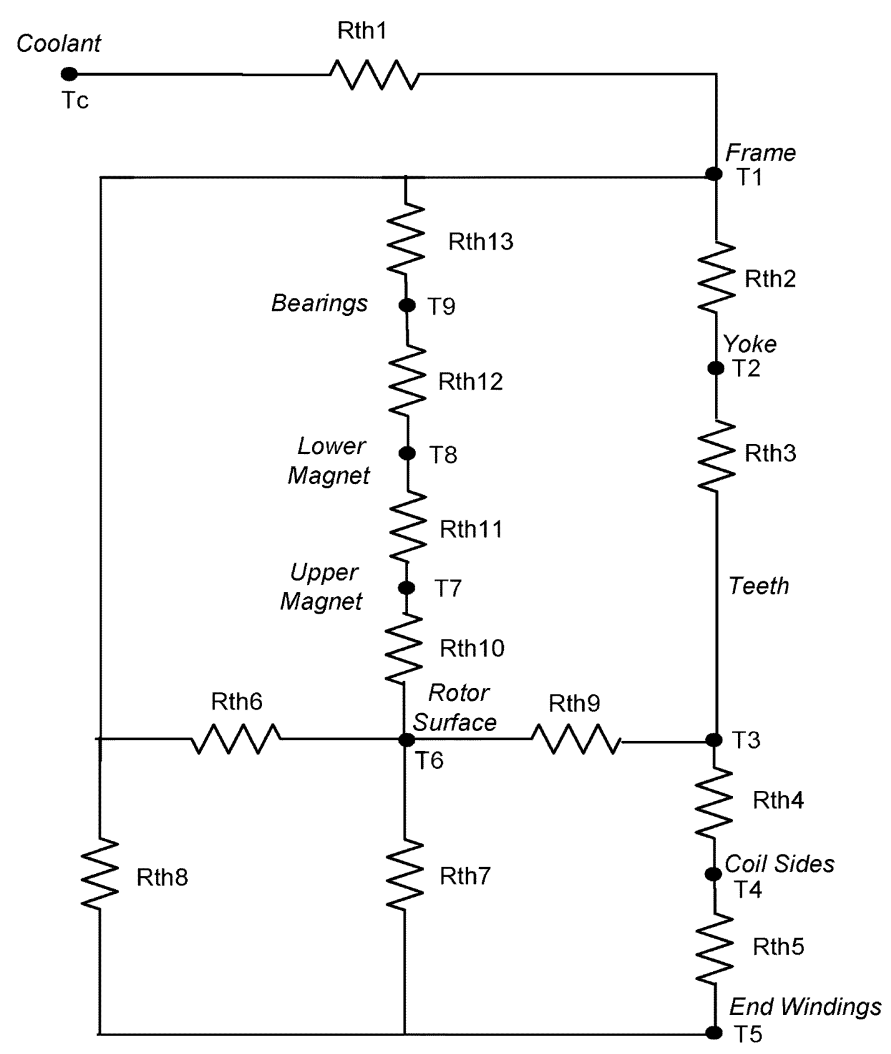

Fig. 3. IPM thermal model network.

One of the basic assumptions of this model is that the liquid cooling jacket surrounding the stator core is sufficiently effective to apply an isothermal constraint $\left(T_{c}\right)$ over the complete stator core surface. Losses can then be injected as currents into any combination of the network nodes in order to determine the temperature (voltage) rise of each machine section with respect to the coolant temperature $\left(T_{c}\right)$.

Key components in the IPM machine whose temperatures are of particular interest for design evaluation include the stator windings and rotor magnets. Two separate nodes are assigned to the stator windings, making it possible to separately estimate the temperatures of the coil sides embedded in the stator core and the end windings. The end windings experience the highest temperature rise of any machine section for both IPM machines analyzed in this paper. Since the rotor magnets are vulnerable to irreversible demagnetization at high temperatures, separate network nodes are allocated to each of the two magnet layers in order to estimate their temperatures.

Network nodes are also assigned to the stator frame, the stator yoke and the bearings to complete the model.

\section{B. Calculation of Rotor Thermal Resistances}

An approximate geometry for the IPM machine rotor is adopted as shown in Fig. 4 to simplify the calculations of the rotor thermal resistances. Based on the observation that heat flow in the actual rotor is principally radial in direction, the approximate geometry is designed so that rotor temperature varies only as a function of radius and not angle. The validity of this assumption and the adopted mapping have been confirmed by detailed finite element analyses presented in Section III. 


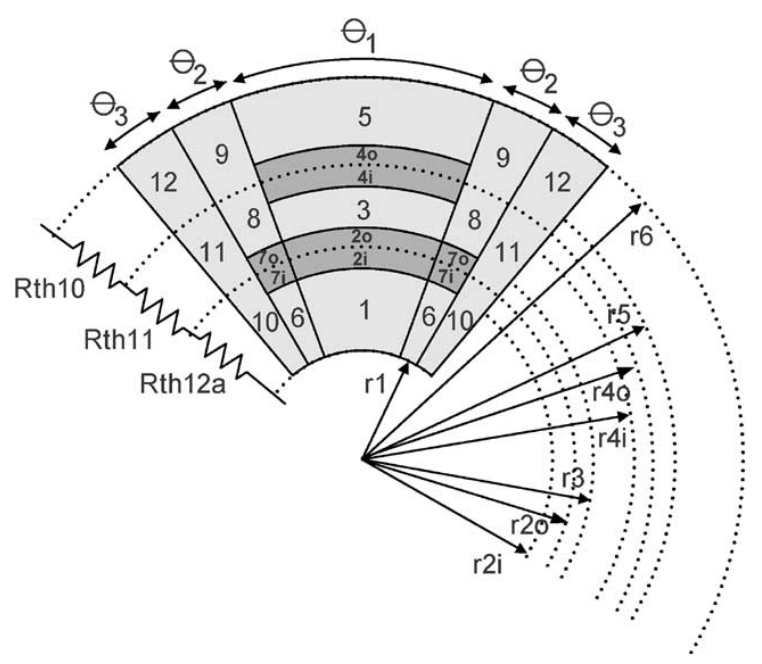

Fig. 4. Simplified geometry of the IPM rotor.

More specifically, the geometrical mapping from Figs. 2-4 consists of replacing the trough-shaped magnets with cylindrical segments. Since the two key parameters governing the magnet radial thermal resistances are their thicknesses and angular spans in the circumferential direction [11], both are preserved in this mapping. The radial positions of the magnets in the approximate geometry match the radii of the central magnet cavity sections in Fig. 2 (e.g., $R 2=r 2 i, R 4=r 4 i$ ).

The two network nodes representing the magnets in Fig. 3 were chosen at the radial midpoints of the two magnet cavities in Fig. 4 (i.e, $r 2 o$ and $r 4 o$ ). Thus, the thermal resistances interconnecting these radial nodes consists of series-parallel combinations of resistances for the numbered cylindrical sections.

The general equation for calculating the radial thermal resistance of a cylindrical section is [11]:

$$
R t h=\frac{\ln \left(\frac{\text { rout }}{\text { rin }}\right)}{2 \pi \lambda L} * \frac{2 \pi}{2 p \theta}
$$

where rout is the outer radius, $\operatorname{rin}$ is the inner radius, $\lambda$ is the thermal conductivity, $p$ is the number of pole pairs, $\theta$ is the angular span, and $L$ is the active length of the machine.

1) Calculation of $R_{t h 12}$ : The thermal resistance $R_{t h 12}$ (see Fig. 5) consists of a series combination of three resistances:

$$
R_{t h 12}=R_{t h 12 a}+R_{t h b}+R_{t h s h}
$$

where $R_{t h 12 a}$ is the rotor radial thermal resistance between radii $r 1$ and $r 2 i$ in Fig. 4, $R_{t h b}$ represents the thermal resistance of the motor bearings between the rotor shaft and the frame, and $R_{t h s h}$ provides the thermal resistance contribution of the axial rotor shaft including the contact resistances at the shaft/bearing and shaft/rotor core interfaces.

All of the individual thermal resistances for the cylindrical sections that contribute to $R_{t h 12 a}$ are calculated using (1). The parameters defining each of these resistances are summarized in Table I. Note that the names of these thermal resistances correspond to the numbered sections in Fig. 4. (The trailing $r$ in each name indicates that they are all radial thermal resistances).

In Table I, $\lambda_{F e}$ is the thermal conductivity of the rotor steel $(51 \mathrm{~W} / \mathrm{mK})$, and $\lambda_{P M}$ is the thermal conductivity of the neodymium-iron magnets $(9 \mathrm{~W} / \mathrm{mK})$.

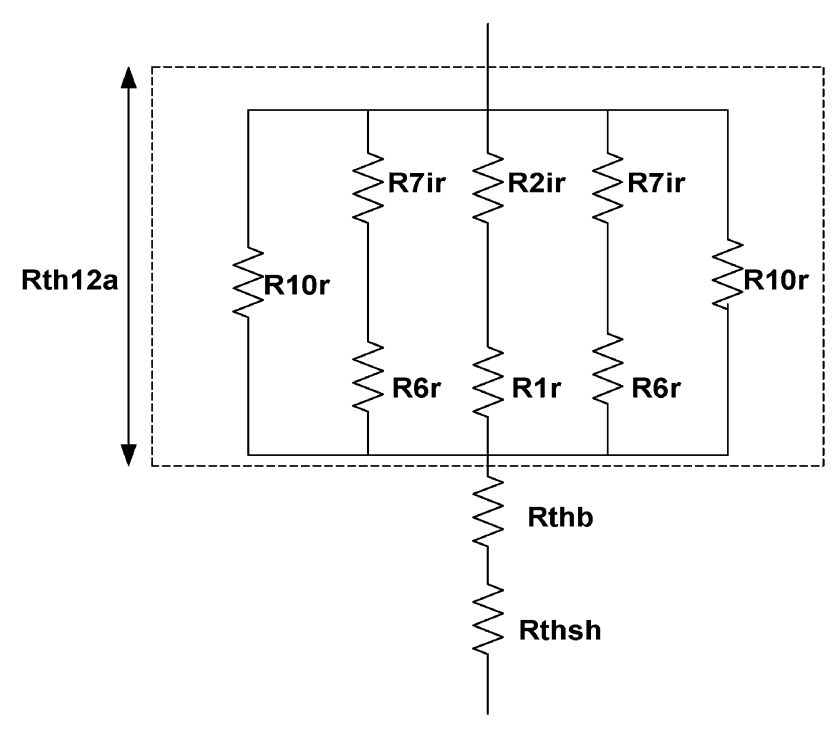

Fig. 5. Equivalent circuit for calculating $R_{t h 12}$.

TABLE I

Thermal Resistances fOR CALCULATING $R_{t h 12 a}$

\begin{tabular}{c|c|c|c|r}
\hline Resistance & rout & rin & $\lambda$ & $\theta$ \\
\hline $\boldsymbol{R} 1 \boldsymbol{r}$ & $r 2 i$ & $r l$ & $\lambda_{F e}$ & $\theta_{1}$ \\
\hline $\boldsymbol{R} 2 \boldsymbol{i r}$ & $r 2 o$ & $r 2 i$ & $\lambda_{P M}$ & $\theta_{1}$ \\
\hline $\boldsymbol{R} 6 \boldsymbol{r}$ & $r 2 i$ & $r l$ & $\lambda_{F e}$ & $\theta_{2}$ \\
\hline $\boldsymbol{R} 7 \boldsymbol{i r}$ & $r 2 o$ & $r 2 i$ & $\lambda_{P M}$ & $\theta_{2}$ \\
\hline $\boldsymbol{R} 10 \boldsymbol{r}$ & $r 2 o$ & $r l$ & $\lambda_{F e}$ & $\theta_{3}$ \\
\hline
\end{tabular}

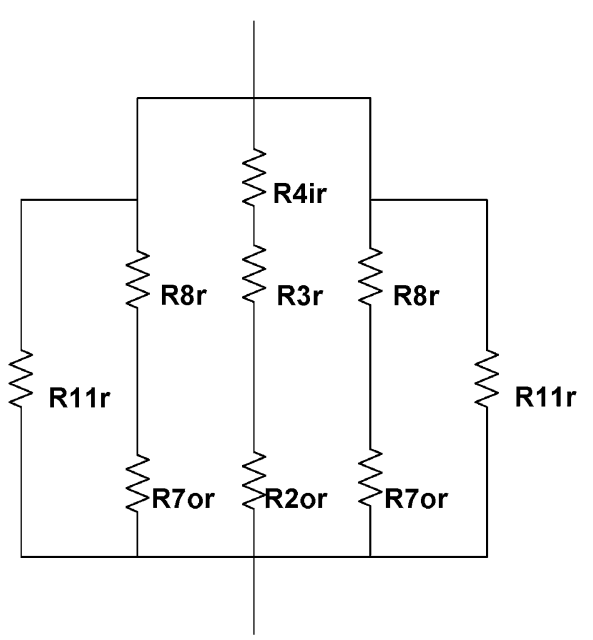

Fig. 6. Equivalent circuit for calculating $R_{t h 11}$.

$R_{t h 12 a}$ is calculated using the Fig. 6 circuit, as follows:

$$
R_{t h 12 a}=\left(\frac{1}{R_{D}}+\frac{2}{R_{E}}+\frac{2}{R 10 r}\right)^{-1}
$$

where

$$
R_{D}=R 1 r+R 2 i r
$$

and

$$
R_{E}=R 6 r+R 7 i r .
$$


TABLE II

THERMAL RESISTANCES FOR CALCULATING $R_{t h 11}$

\begin{tabular}{c|c|c|c|c}
\hline Resistance & rout & rin & $\lambda$ & $\theta$ \\
\hline $\boldsymbol{R 2 o r}$ & $r 3$ & $r 2 o$ & $\lambda_{P M}$ & $\theta_{1}$ \\
\hline $\boldsymbol{R 3 r}$ & $r 4$ & $r 3$ & $\lambda_{F e}$ & $\theta_{1}$ \\
\hline $\boldsymbol{R 4 i r}$ & $r 4 o$ & $r 4 i$ & $\lambda_{P M}$ & $\theta_{1}$ \\
\hline $\boldsymbol{R} 7 \boldsymbol{r} \boldsymbol{r}$ & $r 3$ & $r 2 o$ & $\lambda_{P M}$ & $\theta_{2}$ \\
\hline $\boldsymbol{R} 8 \boldsymbol{r}$ & $r 4 o$ & $R 3$ & $\lambda_{F e}$ & $\theta_{2}$ \\
\hline $\boldsymbol{R} 11 \boldsymbol{r}$ & $r 4 o$ & $r 2 o$ & $\lambda_{F e}$ & $\theta_{3}$ \\
\hline
\end{tabular}

TABLE III

THERMAL Resistances FOR CALCULATING $R_{t h 10}$

\begin{tabular}{c|c|c|c|r}
\hline Resistance & rout & rin & $\lambda$ & $\theta$ \\
\hline R4or & $r 5$ & $r 4 o$ & $\lambda_{P M}$ & $\theta_{1}$ \\
\hline $\boldsymbol{R 5 r}$ & $r 6$ & $r 5$ & $\lambda_{F e}$ & $\theta_{1}$ \\
\hline $\boldsymbol{R} 9 \boldsymbol{r}$ & $r 6$ & $r 4 o$ & $\lambda_{F e}$ & $\theta_{2}$ \\
\hline $\boldsymbol{R} 12 \boldsymbol{r}$ & $r 6$ & $r 4 o$ & $\lambda_{F e}$ & $\theta_{3}$ \\
\hline
\end{tabular}

No changes were made to the approach developed by Lindström [10] to model the thermal impedance contributions of the bearings, the axial rotor shaft, and the contact resistances. The interested reader is referred to this earlier work for more details regarding the thermal modeling of these elements. Ball bearings were assumed and a model is provided in [10] to characterize the radial thermal impedance between the bearing races as a function of rotor speed.

2) Calculation of $R_{t h 11}$ : A similar procedure is used to calculate $R_{t h 11}$ which is the equivalent radial thermal resistance of the rotor between the midpoint radii of the two magnets ( $r 2 o$ and $r 4 o$ in Fig. 4). As in the case of $R_{t h 12 a}$ discussed above, all of the thermal resistances constituting $R_{t h 11}$ are calculated using (1). The names and parameters defining these resistances are summarized in Table II.

Using the equivalent circuit shown in Fig. 6 and resistances listed in Table II, $R_{t h 11}$ can be calculated as follows:

$$
R_{t h 11}=\left(\frac{1}{R_{G}}+\frac{2}{R_{H}}+\frac{2}{R 11 r}\right)^{-1}
$$

where

$$
\begin{aligned}
& R_{G}=R 2 o r+R 3 r+R 4 i r \\
& R_{H}=R 7 o r+R 8 r .
\end{aligned}
$$

3) Calculation of $R_{t h 10}$ : The same procedure is used to calculate $R_{t h 10}$ which is the equivalent radial thermal resistance of the rotor portion between the midpoint radius of the upper magnet ( $r 4 o$ in Fig. 4) and the rotor surface.

All the thermal resistances constituting $R_{t h 10}$ are calculated using (1). The names and parameters of these resistances are summarized in Table III.

Using the equivalent circuit in Fig. 7 and the resistances listed in Table III, $R_{t h 10}$ can be calculated as follows:

$$
R_{t h 10}=\left(\frac{1}{R_{J}}+\frac{2}{R 9 r}+\frac{2}{R 12 r}\right)^{-1}
$$

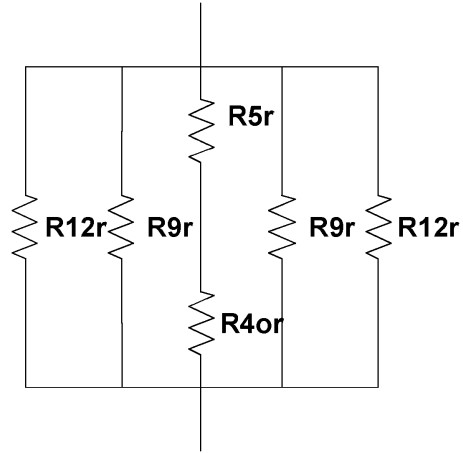

Fig. 7. Equivalent circuit for calculating $R_{t h 10}$.

where

$$
R_{J}=R 4 o r+R 5 r .
$$

\section{Node Temperature Calculations}

For steady-state thermal analysis, the temperature rise of the Fig. 3 network nodes relative to the reference node $\left(T_{c}\right)$ can be calculated as follows:

$$
\bar{\Theta}=\underline{G}^{-1} \bar{P}
$$

where $\bar{P}$ is the power loss vector containing the losses at each node and $\bar{\Theta}$ is the temperature rise vector. The thermal resistances of the Fig. 3 model are used to generate the $10 \times 10$ thermal conductance matrix $G$ which is defined as:

$$
\underline{G}=\left[\begin{array}{cccc}
\sum_{i=1}^{n} \frac{1}{R_{1, i}} & -\frac{1}{R_{1,2}} & \cdots & \frac{-1}{R_{1, n}} \\
-\frac{1}{R_{2,1}} & \sum_{i=1}^{n} \frac{1}{R_{2, i}} & \cdots & -\frac{1}{R_{2, n}} \\
\vdots & \vdots & \ddots & \vdots \\
-\frac{1}{R_{n, 1}} & -\frac{1}{R_{n, 2}} & \cdots & \sum_{i=1}^{n} \frac{1}{R_{n, i}}
\end{array}\right]
$$

where the $n$th diagonal element is the sum of the network conductances connected to node $n$, and $\underline{G}(i, j)$ is the negative of the thermal conductance between nodes $i$ and $j$. An iterative process is generally required to solve for the temperature rise vector $\bar{\Theta}$ because one or more of the conductance matrix components are functions of temperature [10].

\section{Finite ElEMEnt Analysis Model EVAluation}

In order to evaluate the model, two different interior PM machines were analyzed using both the lumped-parameter model and thermal finite element analysis (FEA), and the results were then compared. One of the machines is a $6 \mathrm{~kW}, 6000 \mathrm{r} / \mathrm{min}$ direct-drive automotive starter-alternator (S/A) machine [1] and the other is a $0.5 \mathrm{~kW}, 5000 \mathrm{r} / \mathrm{min}$ IPM machine designed for an electric water pump application [12]. The key dimensions and ratings of both machines are included in Table VI in the Appendix. The ratings and physical dimensions of these machines are sufficiently different to provide a sound basis for evaluating the thermal model.

In both cases, the calculated losses of the machines [2] under specified operating conditions were used as the thermal model inputs. These operating point losses are tabulated in Table VII 


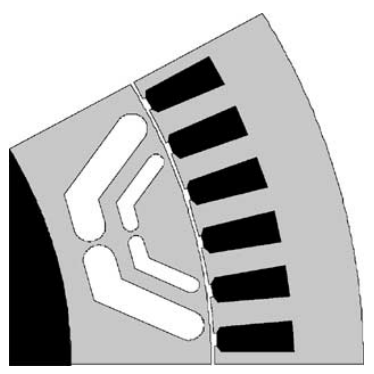

Fig. 8. Cross-section of one pole of the $6 \mathrm{~kW} \mathrm{S/A} \mathrm{machine.}$

in the Appendix. The three major sources of losses are stator winding losses, stator core losses, and slot-induced harmonic losses in the rotor. Mechanical losses including windage and friction are generally small in comparison to these other loss components [13] and were not included in this analysis.

The stator winding losses are calculated using the operating point rms phase current values and the predicted phase resistances. The phase resistances are calculated from the basic machine dimensions and winding configuration. The core loss model includes both hysteresis and eddy-current iron loss components. Core losses are calculated as a function of magnetic flux density and excitation frequency using a Steinmetz equation approach [14]. The method for calculating the slot-induced harmonic core losses follows the approach outlined in [14] directly.

Since the analytical model does not provide a detailed localization of the rotor losses, a worst-case assumption was adopted by concentrating all of the rotor losses in the two magnet layers (50\% in each). Bearing losses are included explicitly in the analysis, and the model adopted to calculate these losses can be found in [10].

\section{A. Starter/Alternator Thermal Analysis Results}

The complete cross-section of this 12-pole machine is shown in Fig. 1 while the cross-section of a single pole is provided in Fig. 8. The operating point selected for this thermal model evaluation is $4 \mathrm{~kW}$ generating at $600 \mathrm{r} / \mathrm{min}$ which corresponds to maximum machine losses, and, hence, maximum expected temperature rise.

The thermal FEA for this machine was performed using two commercial 2-dimensional packages, Flux2D (Magsoft) and ThermNet (Infolytica). The coolant temperature $\left(T_{c}\right)$ is assumed to be $65^{\circ} \mathrm{C}$. Since the FEA results using Flux2D and ThermNet were almost identical, only the ThermNet results are shown in Fig. 9.

The predicted temperature results using both the model and FEA are summarized in Table IV. The temperature difference between the two magnet layers was so small that only one magnet temperature is included in this table.

Since 2-dimensional FEA packages were used, the predicted temperatures of the end windings and bearings could not be conveniently evaluated via FEA. Nevertheless, there is reason for confidence in these predictions based on the previous work of Lindström [10]. The model adopted here for the end windings comes directly from this earlier work that experimentally validated the end winding temperatures for a surface PM syn-

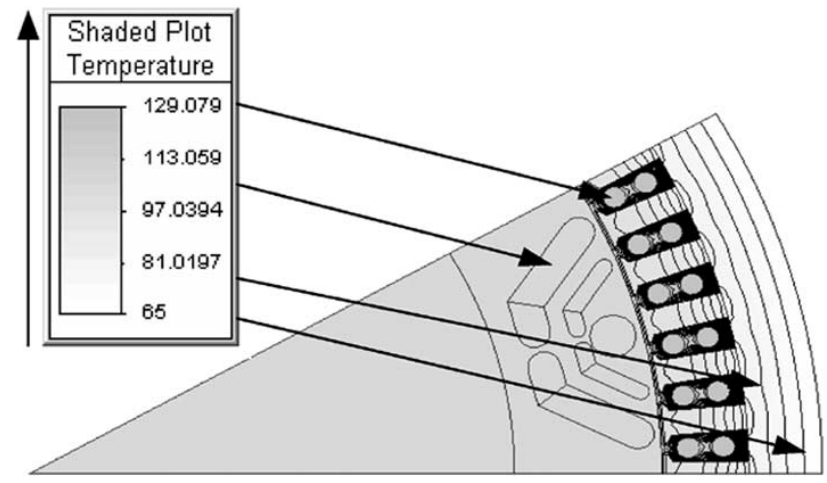

Fig. 9. FEA (ThermNet) results for the S/A machine at $4 \mathrm{~kW}, 600 \mathrm{r} / \mathrm{min}$.

TABLE IV

PREDiCTED TEMPERATURES FOR THE S/A AT 4 KW, 600 R/MIN

\begin{tabular}{|c|c|c|c|c|c|}
\hline & Frame & Yoke & Teeth & Coil & $\begin{array}{c}\text { End } \\
\text { Wdg. }\end{array}$ \\
\hline Model $\left[{ }^{\circ} \mathrm{C}\right]$ & 65.56 & 81.81 & 100.4 & 128.1 & 163.7 \\
\hline Flux $2 \mathrm{D}\left[{ }^{0} \mathrm{C}\right]$ & 65 & 76.67 & 96.11 & 127.2 & - \\
\hline ThermNet $\left[{ }^{0} \mathrm{C}\right]$ & 65 & 76 & 97 & 128.8 & - \\
\hline & Magnet & Bearings & & & \\
\hline $\operatorname{Model}\left[{ }^{0} \mathrm{C}\right]$ & 97.39 & 79.9 & & & \\
\hline Flux2D $\left[{ }^{0} \mathrm{C}\right]$ & 103.9 & - & & & \\
\hline ThermNet $\left[{ }^{\circ} \mathrm{C}\right]$ & 103.5 & - & & & \\
\hline
\end{tabular}

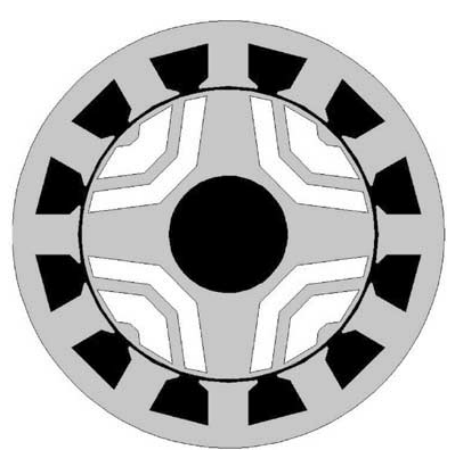

Fig. 10. Cross section of the electric water pump machine.

chronous machine. Sensitivity analysis has shown that the temperature of the end windings is mainly affected by the values of stator-side thermal resistances $R_{t h 3}, R_{t h 4}$, and $R_{t h 5}$. Since the stator structure of the surface PM synchronous machine and the interior PM synchronous machine is the same, the verification results presented in [10] provide a basis for confidence in the predicted end winding temperatures presented here.

The temperature predictions using the lumped-parameter model and the FEA are within $7 \mathrm{degC}$ or less for all of the key nodes for which comparisons are possible. Subsequent investigation has revealed that the magnet temperature difference is caused by the fact that shaft heat flow is not accounted for in the 2-D FEA. The demonstrated level of agreement builds confidence in the usefulness of the model for initial IPM machine design evaluations.

\section{B. Electric Water Pump Thermal Analysis Results}

A cross-section of the $0.5 \mathrm{~kW}, 5000 \mathrm{r} / \mathrm{min}$ electric water pump IPM machine is provided in Fig. 10. FEA results using Flux2D are shown in Fig. 11 for rated operation with a coolant temper- 


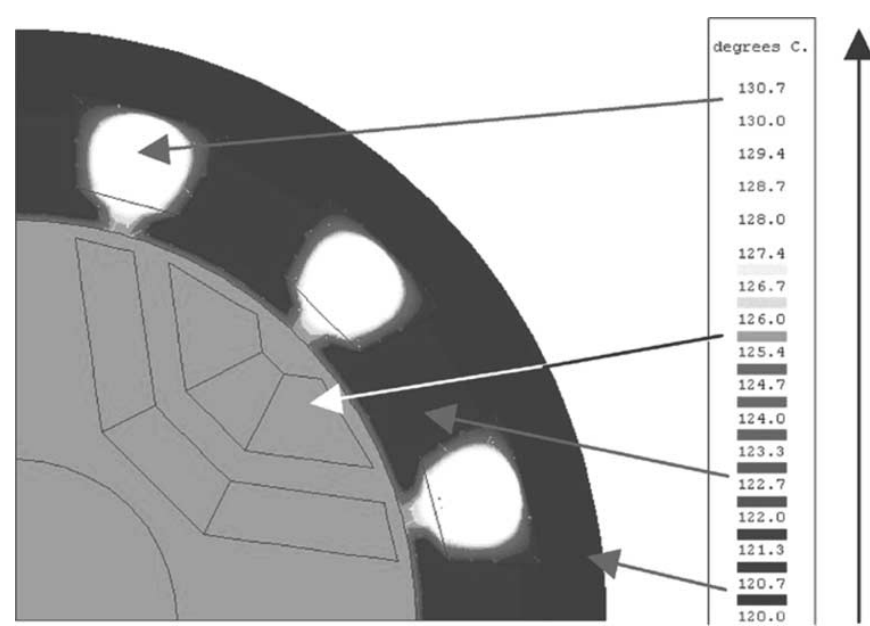

Fig. 11. FEA (Flux2D) results for the electric water pump machine operating at $500 \mathrm{~W}, 5000 \mathrm{r} / \mathrm{min}$.

TABLE V

PREDICTED TEMPERATURES FOR THE ELECTRIC WATER PUMP IPM MACHINE AT $0.5 \mathrm{KW}$ AND $5000 \mathrm{R} / \mathrm{MIN}$

\begin{tabular}{|c|c|c|c|c|c|}
\hline & Frame & Yoke & Teeth & Coil & $\begin{array}{r}\text { End } \\
\text { Wdg. }\end{array}$ \\
\hline Model $\left[{ }^{\circ} \mathrm{C}\right]$ & 120 & 121.53 & 123.1 & 128.6 & 135.1 \\
\hline Flux2D $\left[{ }^{\circ} \mathrm{C}\right]$ & 120 & 120.3 & 122.0 & 130.6 & - \\
\hline & Magnet & Bearings & & & \\
\hline Model $\left[{ }^{0} \mathrm{C}\right]$ & 126.3 & 127.2 & & & \\
\hline Flux2D $\left[{ }^{0} \mathrm{C}\right]$ & 125.6 & - & & & \\
\hline
\end{tabular}

ature of $120 \mathrm{degC}$. Temperature prediction results for the two analytical approaches are summarized in Table V (Only Flux $2 \mathrm{D}$ was used in this case). Agreement between the results of the lumped-parameter model and FEA is very good.

\section{IPM MACHINE DESIGN OPTIMIZATION PROCESS}

As noted in the Introduction, the intended purpose of the new lumped-parameter thermal model is to provide fast predictions of internal IPM machine temperatures as part of an iterative Monte Carlo design optimization algorithm.

A simplified flowchart for this design process is shown in Fig. 12. As indicated in this figure, a candidate machine design is first evaluated against the electrical performance specifications. If it meets these requirements, the thermal model is used to predict the temperatures of the stator windings and magnets to determine whether they exceed their limits. Any candidate design that does not meet these thermal requirements is rejected.

By evaluating a sufficiently large number of randomly-generated candidate design, the small percentage of designs that successfully meet both the performance and thermal requirements can then be compared to choose the "optimal" design. Although minimum cost is the principal optimization objective for automotive applications, a range of other metrics (e.g., efficiency, weight) can also be used for other applications.

\section{Model Modifications and Extensions}

The lumped parameter model discussed in this paper is quite flexible, making it possible to modify and extend it for other applications. Some of possibilities include:

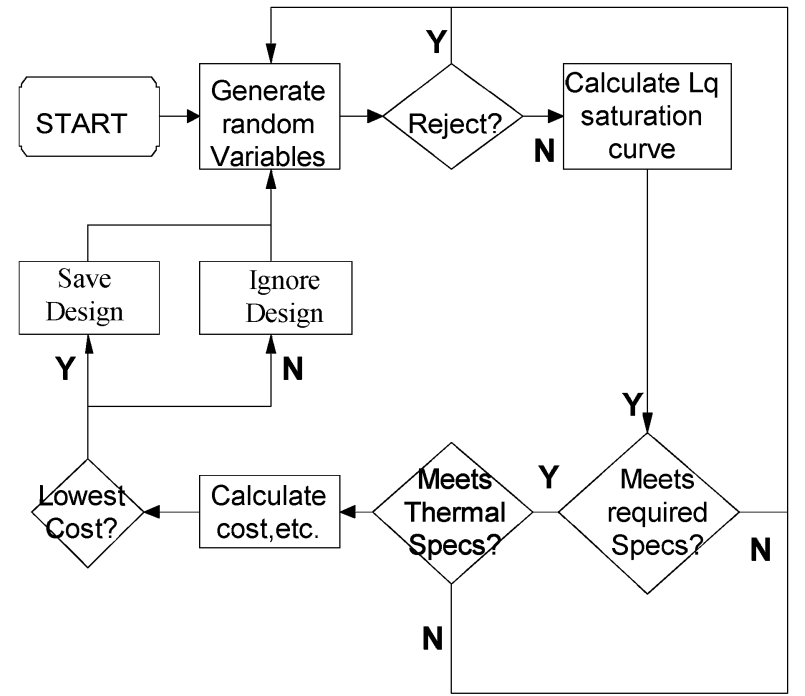

Fig. 12. IPM machine design optimization flowchart.

TABLE VI

KEY PARAMETERS/DIMENSIONS FOR THE 6 KW, 6000 R/MIN STARTER/ALTERNATOR AND $0.5 \mathrm{KW}, 5000 \mathrm{R} / \mathrm{MIN}$ WATER PUMP MACHINES

\begin{tabular}{c|c|c|c}
\hline Parameter & S/A & Water Pump & Units \\
\hline Base Current & 327 & 13.7 & Amps \\
\hline Base Voltage & 19.3 & 14.5 & Volts \\
\hline Number of poles & 12 & 4 & poles \\
\hline Stator outer diameter & 0.2717 & 0.0817 & $\mathrm{~m}$ \\
\hline Active length & 0.06 & 0.0712 & $\mathrm{~m}$ \\
\hline Rotor outer radius & 0.1084 & 0.0277 & $\mathrm{~m}$ \\
\hline Rotor inner radius & 0.0831 & 0.0112 & $\mathrm{~m}$ \\
\hline Air gap thickness & 0.000635 & 0.0006 & $\mathrm{~m}$ \\
\hline Magnet remanence & 0.28 & 0.35 & $\mathrm{~T}$ \\
\hline
\end{tabular}

TABLE VII

CAlculated Losses FOR THE S/A MACHINE @ 4KW, 600 R/MIN) AND THE WATER PUMP MACHINE @ 0.5 KW, 5000 R/MIN)

\begin{tabular}{c|c|c}
\hline Losses & S/A & Water Pump \\
\hline Armature $[W]$ & 1609.8 & 50.38 \\
\hline Teeth core $[W]$ & 3.65 & 7.26 \\
\hline Back Iron core $[W]$ & 8.81 & 17.51 \\
\hline Rotor harmonic $[W]$ & 33.25 & 2.94 \\
\hline Bearing $[W]$ & 3 & 25 \\
\hline
\end{tabular}

1) Convection Cooling. The model can be readily adapted for natural or forced-air convention cooling by recalculating $R_{t h 1}$ in Fig. 3 using convection-based heat transfer expressions [11] to replace the combination of conduction and convection expressions [10] used for water cooling.

2) Magnet Layer Number. The same procedure described in this paper can be used to either increase the number of rotor magnet layers to more than two or to reduce it to a single layer.

3) Transient Thermal Analysis. A third possibility is to extend this lumped-parameter thermal model for transient thermal analysis. The approach for calculating the necessary thermal capacitances can be found in [10].

\section{CONCLUSIONS}

A lumped-parameter thermal model for multi-barrier IPM synchronous machine has been presented that makes it possible 
to predict the temperatures of key points inside the machine including the stator windings and the rotor magnets. By reducing the number of model nodes to ten, this model strikes an appealing balance between prediction accuracy and model complexity, making this model attractive for initial machine design evaluations.

Results have been presented for two IPM machine designs comparing the thermal predictions of the lumped-parameter model and two-dimensional finite element analysis. The agreement between the thermal predictions provided by the two analytical techniques is quite good, raising confidence in the usefulness of the lumped-parameter model for evaluating new IPM machine designs.

\section{APPENDIX}

\section{See Tables VI and VII.}

\section{ACKNOWLEDGMENT}

The authors would like to thank GM Advanced Technology Center and the Wisconsin Electric Machines and Power Electronics Consortium and for their support. The authors would also like to thank J. Lindström and Prof. J. Luomi [10] for their generous assistance.

\section{REFERENCES}

[1] E. C. Lovelace, T. M. Jahns, J. L. Kirtley Jr., and J. H. Lang, "An interior PM starter/alternator for automotive applications," in Proc. Int. Conf. Elect. Mach., vol. 3, 1998, pp. 1802-08.

[2] E. C. Lovelace, "Optimization of Magnetically Saturable Interior Permanent-Magnet Synchronous Machine Drive," Ph.D. dissertation, MIT, Cambridge, MA, 2000.

[3] I. J. Perez and J. K. Kassakian, "A stationary thermal model for smooth air-gap rotating electrical machines," Elect. Mach. Electromechanics, vol. 3, pp. 285-303, 1979.

[4] P. H. Mellor, D. Roberts, and D. R. Turner, "Lumped parameter thermal model for electrical machines of TEFC design," Proc. Inst. Elect. Eng. $B$, vol. 138, no. 5, Sept. 1991.

[5] P. H. Mellor and D. R. Turner, "Real time prediction of temperatures in an induction motor using a microprocessor," Elect Mach. Power Syst., vol. 13 , pp. 333-352, 1988 .

[6] P. H. Mellor, D. R. Turner, and D. Roberts, "Microprocessor based induction motor thermal protection," in Proc. 2nd Int. Conf. Elect. Mach., Design Applicat., 1985, IEEE Conf. Publ. 254, pp. 16-20.

[7] C. R. Soderberg, "Steady flow of heat in large turbine generators," AIEE Trans., vol. 50, pp. 787-802, June 1931.

[8] Z. J. Liu, D. Howe, P. H. Mellor, and M. K. Jenkins, "Thermal analysis of permanent magnet machines," in Proc. 6th Int. Conf. Elect. Mach. Drives, 1993, pp. 359-364.

[9] G. R. Slemon and X. Liu, "Modeling and design optimization of permanent magnet motors," Elect. Mach. Power Syst., vol. 20, no. 2, pp. 77-92, Mar. 1992

[10] J. Lindström. (1999) Thermal Model of a Permanent-Magnet Motor for a Hybrid Electric Vehicle. Research Report, Dept. of Electric Power Eng., Chalmers Univ. Technol., Göteborg, Sweden. [Online]. Available: http://www.elkraft.chalmers.se/Publikationer/EMKE.publ/Abstracts/Lindstrom_5_.pdf

[11] F. P. Incropera and D. P. DeWitt, Fundamentals of Heat and Mass Transfer. New York: Wiley, 1990.

[12] N. C. Harris, T. M. Jahns, and S. Huang, "Design of an integrated motor/controller for an automotive water pump application," in Proc. IEEE Industry Appl. Soc. Annu. Meeting, Pittsburgh, PA, Oct. 2002.

[13] A. E. Fitgerald, J. C. Kingsley, and S. D. Umans, Electric Machinery. New York: McGraw-Hill, 1990.

[14] H. W. Beaty and J. L. Kirtley Jr., Electric Motor Handbook. New York: McGraw-Hill, 1998.

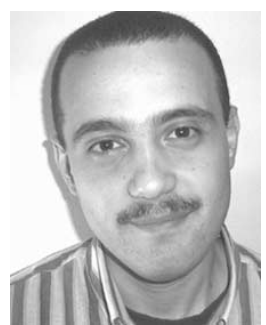

Ayman M. El-Refaie (S'95) received the B.Sc. and M.Sc. degrees in electrical power engineering from Cairo University, Cairo, Egypt, in 1995 and 1998, respectively. He received the M.Sc. degree in electrical engineering from the University of Wisconsin-Madison, Madison, in 2002. He is currently pursuing the Ph.D. degree at the University of Wisconsin-Madison in the Wisconsin Electric Machines and Power Electronics Consortium (WEMPEC) Group.

Currently, he is a Research Assistant at the University of Wisconsin-Madison. From 1995 to 1998, he was an Assistant Lecturer with Cairo University and the American University, Cairo, Egypt. He participated in many projects involving the design of electrical power distribution systems. His interests include electrical machines and drives.

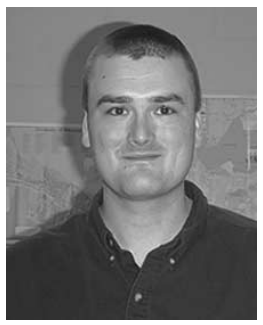

Nathan C. Harris received the B.Sc. degree in Physics from the University of Wisconsin, Eau Claire, in 1998, and the M.Sc. degree in electrical engineering from University of Wisconsin-Madison, Madison, in 2001

Currently, he is an Electrical Engineer with Kimberly Clark Corporation, Neenah, WI. From 1997 to 1998, he was with Argonne National Laboratory, Chicago, IL, performing research on high-temperature superconductor and working with data-acquisition systems. His interests include machine control, sensors, data-acquisition systems, and drives.

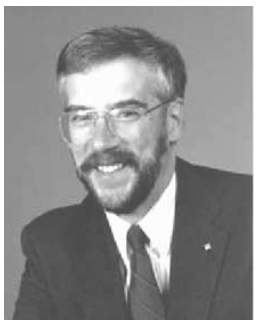

Thomas M. Jahns (S'73-M'79-SM'91-F'93) received the S.B. and S.M. degrees in electrical engineering in 1974 and the Ph.D. degree in electrical engineering from the Massachusetts Institute of Technology, Cambridge, in 1978.

Currently, he is a Professor in the Department of Electrical and Computer Engineering at the University of Wisconsin-Madison, Madison, where he is also Associate Director of the Wisconsin Electric Machines and Power Electronics Consortium (WEMPEC). Prior to coming to the University of Wisconsin-Madison, he was with GE Corporate Research and Development, Schenectady, NY, for 15 years, where he pursued new power electronics and motor drive technology in a variety of research and management positions. From 1996 to 1998, he conducted a research sabbatical at the Massachusetts Institute of Technology, where he directed research activities in the area of advanced automotive electrical systems and accessories as co-director of an industry-sponsored automotive consortium. His research interests include permanent magnet synchronous machines for a variety of applications ranging from high-performance machine tools to low-cost appliance drives.

Dr. Jahns was awarded the William E. Newell Award by the IEEE Power Electronics Society (PELS) in 1999. He has been recognized as a Distinguished Lecturer by the IEEE Industry Applications Society (IAS) during 1994-1995 and by IEEE-PELS from 1998 to 1999 . He has served as President of PELS (1995-1996) and as a member of the IAS Executive Board from 1992 to 2001.

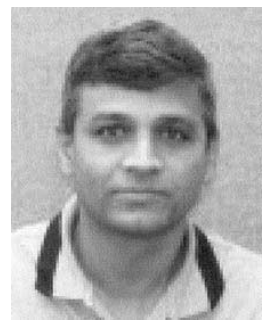

Khwaja M. Rahman (S'93-M'99) received the B.Sc. and the M.Sc. degrees in electrical engineering from Bangladesh University of Engineering and Technology (BUET), Dhaka, Bangladesh, in 1987 and 1990, respectively, and the M.S. and Ph.D. degrees in electrical engineering from Texas A\&M University, College Station, in 1992 and 1998, respectively.

In 1998, he joined the General Motors Advanced Technology Center (GMATC), Torrance, CA, as a Research Engineer. From 1987 to 1990, he was a Lecturer with the electrical engineering department of BUET. His research interests include adjustable speed drives, electric and hybrid electric vehicle propulsion systems, and microcomputer control of drives.

Dr. Rahman is a member of Phi Kappa Phi. 